\title{
Gizli Kalmış Bir Enerji Kaynağı: Kargı Kamışı (Arundo donax L.)
}

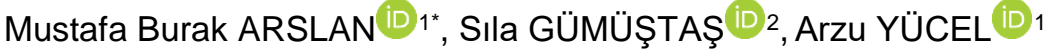 \\ ${ }^{1}$ Ege Ormancılık Araştırma Enstitüsü Müdürlüğü, İzmir \\ ${ }^{2}$ Ege Üniversitesi, Fen Fakültesi, İzmir \\ Geliş Tarihi (Received): 21.01.2021, Kabul Tarihi (Accepted): 13.04.2021 \\ $\square$ Sorumlu Yazar (Corresponding author $\left.{ }^{\star}\right):$ mustafaburakarslan@ogm.gov.tr \\ (C) +902327663495 且 +902327663499
}

\section{ÖZ}

Fosil esaslı yakıtlar dünyanın enerji intiyacını karşılamakla birlikte atmosfere başta karbondioksit olmak üzere sera etkisi yapan gazlar salmaktadır. Son çeyrek asıra gelindiğinde, özellikle doğrudan yakma sistemlerinde biyokütle enerjisinin önem kazandığı görülmektedir. Biyokütle enerji üretiminde hammadde sürekliliği mühim bir husustur. Bu noktada farklı ekolojik koşullarda rahatça yetişebilen çok yıllık bir C3 bitkisi olan kargı kamışı (Arundo donax L.) başta Güney Avrupa ve Kosta Rika olmak üzere dünyanın çeşitli ülkelerinde büyük ilgi çekmektedir. Uygun koşullarda hektarda 100 tona kadar biyokütle verebilen kargı kamışının ısıl değeri de $17.200-20.600 \mathrm{kj} / \mathrm{kg}$ arasıdır. Bu çalışmada ülkemizde yöresel kullanımın ötesine geçemeyen kargı kamışının doğrudan yakma sisteminde kullanılabilirliği literatürdeki çalışmalar ışığında mercek altına alınmıştır. Bu inceleme ile; kargı kamışının genel özellikleri ve kullanım alanları, kimyasal karakterizasyonu, biyokütle miktarı ve ısıl değeri olmak üzere üç ana çerçevede derlenerek, kargı kamışının doğrudan yakma sistemlerinde kullanımının endüstriye aktarılmasına teknik alttık oluşturulmaya çalışılmıştır.

Anahtar Kelimeler: Arundo donax L., biyokütle enerjisi, doğrudan yakma, kargı kamışı

\section{A Hidden Energy Source: Giant Reed (Arundo donax L.)}

\begin{abstract}
Fossil-based fuels while supply the energy needs of the world, on the other hand release greenhouse gases, especially carbon dioxide, into the atmosphere. In the last quarter century, biomass energy has gained importance, particularly in direct combustion systems. The continuity of raw material is an important matter in biomass energy production. At this point, giant reed (Arundo donax L.), a perennial C3 plant that can be easily grown in different ecological conditions, has drawn considerable interest in various countries of the world, mainly in Southern Europe and Costa Rica. The calorific value of the giant reed, which can deliver up to 100 tons of biomass per hectare under suitable conditions, is between $17,200-20,600 \mathrm{kj} / \mathrm{kg}$. In this study, the usability of the giant reed, this unable to exceed the local usage in our country, in combustion systems was examined in the light of the studies in the literature. This review had been compiled under three main frameworks as general properties and usage areas, chemical characterization, biomass amount and calorific value of the giant reed. Thus, it had been tried to form a technical basis for the industrial usage of giant reed in combustion systems.
\end{abstract}

Keywords: Arundo donax L., biomass energy, direct combustion, giant reed 


\section{GíRiş}

İnsan nüfusundaki artış, teknolojideki ilerlemeler ve sanayileşmedeki yükseliş beraberinde fosil esaslı yakıtların kullanımını arttırmıştır. Fosil esaslı yakıtların enerji amaçlı kullanılması neticesinde binlerce yıl süresince toprak altında biriken karbon bir anda atmosfere salınmakta ve karbon döngüsü olumsuz etkilenmektedir. Bununla birlikte atmosfere karbondioksit başta olmak üzere sera etkisi yapan gazlar da salınmaktadır. Fosil esası ı kaynakların bir diğer dezavantajı yenilenebilir olmayışıdır. Bir başka ifade ile fosil esaslı kaynaklar dünya enerji intiyacını karşılamakla birlikte sınırsız olmayıp, doğaya ve atmosfere de zarar vermektedir. Bu noktada yenilenebilir enerji kaynaklarının önemi ortaya çıkmaktadır. En önemli yenilenebilir enerji kaynaklarından birisi de biyokütle enerjisidir. Biyokütle; fotosentez yoluyla güneş enerjisinin etkisi ile canlı organizmalarda çoğunlukla selüloz ve lignin olarak depolanan canlı kütle olarak tanımlanabilir (Arslan, 2011). Diğer yandan biyokütle enerjisi, rezerv kısıtı olmadığı gibi çeşitli amaçlarla üretimi ve sürekliliği kolay sağlanabilir kaynaklar bulunduğu takdirde günümüz için alternatif bir enerji türüdür. Süreklilik bakımından odun ve enerji bitkileri biyokütle enerjisinin en önemli hammadde kaynaklarıdır. Fosilleşmemiş biyolojik kökenli materyal olarak da tanımlanan biyokütle, çeşitli metotlar kullanılarak ısı ve enerji eldesinde kullanılabilmektedir. Yağ, şeker ve/veya selüloz içeriği diğer bitkilere göre daha yüksek, bununla beraber birim alanda yüksek miktarda kuru madde üretme kapasitesine sahip bitkilere enerji bitkileri denmektedir. Kargı kamışı (Arundo donax L.) her geçen gün önemini arttıran bir enerji bitkisi olarak dikkat çekmektedir.

Farklı ekolojik koşullarda kendiliğinden yetişen çok yıllık bir C3 bitkisi olan kargı kamışı (Arundo donax L.), Gramineae familyasının Arundinoideae alt familyasındandır. Kökeni konusunda tam bir fikir birliği yoktur. Akdeniz kuşağı bitkisi olarak kabul edilmesinin yanı sıra orijininin Doğu Asya olduğuna dair görüşler de mevcuttur. Kargı kamışı binlerce yıldır Asya, Amerika ve Afrika'da doğal olarak yetişmekle birlikte 19. yüzyıldan itibaren Amerika ve Avustralya'da plantasyonları kurulmaya başlanmıştır (Quinn ve Holt, 2008; Arslan ve Şahin, 2014).
Kısır bir bitki olan kargı kamışı tohum üretmez ve eşeysiz vejatatif üreme sistemine sahiptir. Ilıman bir iklimde kargı kamışının yaşam döngüsü rizomlardan yeni kamışların filizlenmesiyle başlar. İlkbaharda çok hızıı büyüyen kargı kamışı önemli bir biyokütle miktarı oluşturarak dünyanın en büyük otsu bitkileri sınıfına girmektedir. Bitkide yaz başında gelişim devam etmekle birlikte, bahardaki büyüme dönemi kadar hızlı ve etkin değildir. Koşullara göre ağustos- ekim arası çiçek açan kargı kamışı, kasım sonu itibariyle yaşlanma periyoduna girerek sararmaktadır. Ancak bitki ölmez ve canIılığını sürdürerek, şubatta yeniden vejetasyon dönemine girer (Şekil1 ve 2). Kargı kamışı 6-12 ay içerisinde, bir başka ifade ile yaz sonu, sonbahar ve kış aylarında hasat edilebilmektedir (Angelini ve ark., 2005; Bezirci, 2007: Odero ve ark., 2011; Corno ve ark., 2014; Salazar-Zeledon ve ark., 2015).

Esas gelişimini nehir, göl, bataklık yanı gibi su ile zengin topraklarda gösteren kargı kamışı aynı zamanda çakıllı, kumlu, killi ve dahası tuzlu topraklarda da gelişebilmektedir. İstilacı bir tür olması ve geniş ekolojik yelpazede kolayca büyüyebilmesi hızlıca yayılmasının önünü açmaktadır. Uygun şartlarda 10 m'ye kadar boy yapabilmesine karşın genel itibariyle 3-6 m boy, $1-4 \mathrm{~cm}$ çap yapan kargı kamışı birçok kullanım amacı için uygun bir hammadde kaynağıdır. Üflemeli çalgı ve bitkisel örücülük en eski ve yaygın kullanım amaçlarıdır. Bununla birlikte, fitoromediasyon (bitkisel arıtım), kağıt hamuru ve kağıt sanayi, lif/yonga levha endüstrisi ve biyokütle enerji üretimi için de oldukça elverişli bir materyal olma özelliğindedir (Perdue, 1958; Gordon ve ark., 2011; Arslan ve Şahin, 2014; Corno ve ark., 2014; Cristaldi ve ark., 2017).

Dünya genelinde büyük bir yayılış alanına sahip olan kargı kamışı (Şekil 3) ülkemizde Ege, Akdeniz, Marmara ve Kuzeydoğu Anadolu bölgelerinde doğal olarak yayılış göstermektedir (Soyak, 2009; Arslan ve ark., 2012).

Bu çalışmanın amacı dünyada gittikçe önemini arttıran ancak ülkemizce yöresel kullanımların ötesine geçemeyen kargı kamışının biyokütle enerjisi üretiminde doğrudan yakma sistemlerinde kullanım olanaklarının incelenmesidir. 
Gizli Kalmış Bir Enerji Kaynağı: Kargı Kamışı (Arundo donax L.)
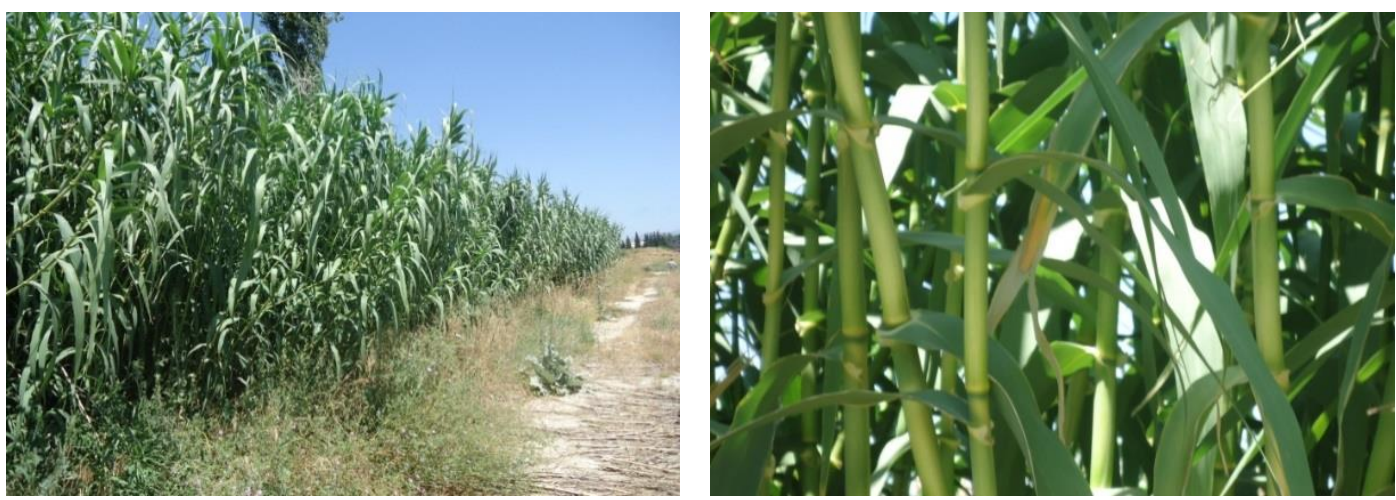

Şekil 1. İzmir Tire doğal kargı sahası (Arslan, 2013)
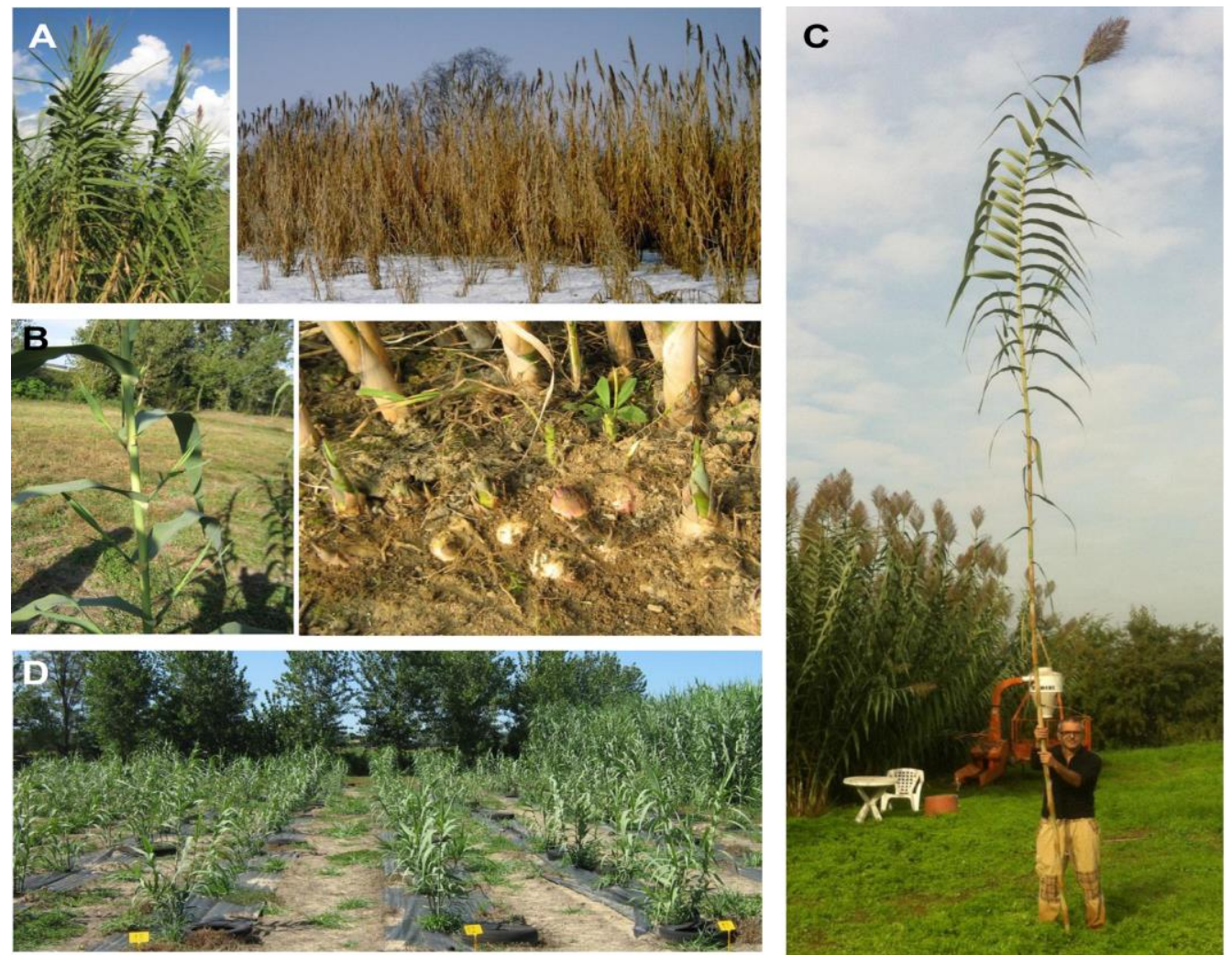

Şekil 2. Kargı kamışının yaşam döngüsü, üremesi ve kültüründen görünümler. A. Yaz (sol) ve kış (sağ) aylarında olgun bitki. B. Kamışlardan sürgünlerin filizlenmesiyle çoğalma (sol) ve rizomla çoğalma (sağ). C. 8 m yüksekliğe ulaşan tek kamış. D. Kargı kamışının kamış çelikleri ile çoğalma kültürü (Pilu ve ark., 2013) 


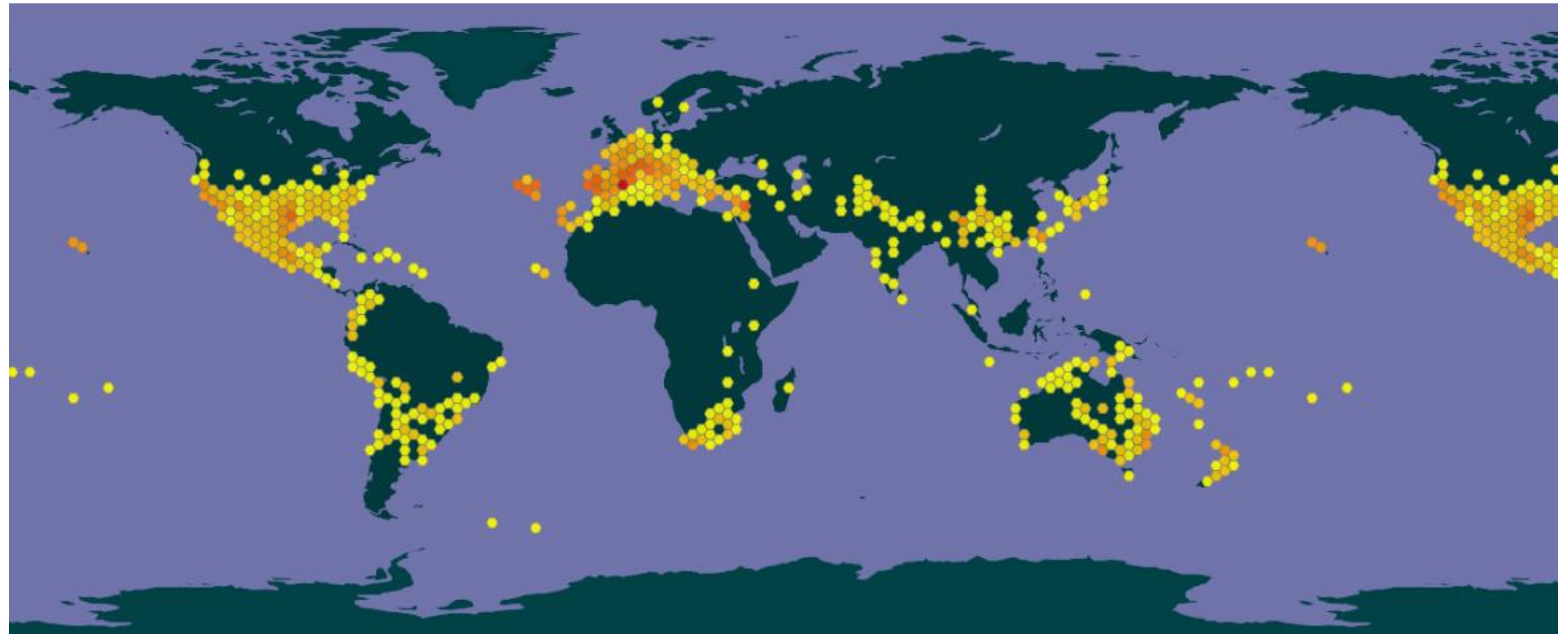

Şekil 3. Kargı kamışının yayılışı (GBIF Secretariat, 2021)

\section{KARGI KAMIŞININ KULLANIM ALANLARI}

Kullanımı binlerce yı öncesine dayanan kargı kamışının en eski kullanım alanı üflemeli çalgı yapımıdır. Tasavvuf müziğinin vazgeçilmez enstrümanı olan ney kargı kamışından yapılmaktadır. Semavi olmayan dinlerde de dinsel ayinlerde kullanıldığı düşünülmektedir (Perdue, 1958; Koca, 2002). Avrupa'da üflemeli çalgı yapımında kargı kamışının kullanımı büyüme göstermektedir. Enstrüman yapımında tercih edilmesinin sebebi ise elastikiyet özelliğinin ve rutubete dayanımının iyi olmasıdır (Odero ve ark., 2011; Pilu ve ark., 2012). Ayrıca idrar yolları, terleme gibi hastalıkların geleneksel tedavisi ile bitkisel örücülük ve dokumacılık gibi el sanatlarında da kullanılmaktadır (Perdue, 1958; Bezirci, 2007; Guarrera, 2008; Gücel, 2010).

Geleneksel kullanımının yanı sıra son çeyrek asırda kargı kamışının endüstriyel olarak farklı kullanım alanlarında değerlendirilmesine yönelik çalışmalara yoğunluk verilmiştir. Kargı kamışı, kağıt hamuru, kağıt, yonga levha, lif levha ve pelet üretimi için oldukça elverişli bir hammadde kaynağıdır (Altheimer ve Wolcott, 1999; Shatalov ve Pereira, 2001; Dahl ve Obernberger, 2004; Ghalehno ve ark., 2011; Ortunõ ve ark., 2011; Tenorio ve ark., 2015; Ramos ve ark., 2017; Ferrandez-García ve ark., 2020). İlaveten kargı kamışı doğrudan yakma, biyo-etanol ve biyo-gaz üretimi için uygun bir materyaldir (Angelini ve ark., 2009; Ragaglini ve ark., 2014; SalazarZeledon ve ark., 2015; Brusca ve ark., 2018). Ayrıca fitoromediasyon için de potansiyeli olan bir bitkidir (Cervelli ve ark., 2016; Cristaldi ve ark., 2017).

\section{KARGI KAMIŞININ KIMYASAL KARAKTERIZAS- YONU}

Kargı kamışının kompozit levha, kağıt hamuru ve biyokütle enerjisi üretiminde kullanım olanakları için kimyasal yapısının bilinmesi büyük önem taşımaktadır. Biyokütle enerjisi üretimi için kimyasal karakterizasyon üç alt başlık altında incelenebilir. Bunlardan ilki temel kimyasal yapı, ikincisi Fourier dönüşümlü kızılötesi (FTIR) spektroskopisi ile yapısal analizi, üçüncüsü termal karakterizasyonudur.

Kargı kamışı lignoselülozik bir materyaldir. Yani; yapısını lignin, selüloz, hemiselüloz ve ekstraktifler oluşturmaktadır. Böyle bir yapıya sahip olması nedeniyle birçok kullanım alanı için avantajlı hale gelmektedir. Bu nedenledir ki; kargı kamışının temel kimyasal yapısının aydınlatılmasına yönelik çok sayıda araştırma yapılmıştır (Tablo 1). 
Gizli Kalmış Bir Enerji Kaynağı: Kargı Kamışı (Arundo donax L.)

Tablo 1. Kargı kamışının temel kimyasal bileşen oranları (\%)

\begin{tabular}{|c|c|c|c|c|l|}
\hline Selüloz & Hemiselüloz & Lignin & Ekstraktif & Kül & Yazar \\
\hline $28,1-32,6$ & $20,5-29,8$ & $15,8-22$ & $14,4-23,2$ & $2,9-3,9$ & Neto ve ark., 1997 \\
\hline $29,2-32,9$ & $28,5-32$ & $20,9-21,3$ & $11,2-13$ & $4,8-6,1$ & Shatalov ve ark., 2001 \\
\hline $30,8-37,7$ & - & $13,4-20,5$ & - & $4,3-5,5$ & Ververis ve ark., 2004 \\
\hline 34,8 & 29,8 & 23 & 9,1 & 3 & Caparròs ve ark., 2007 \\
\hline 34,8 & 20,9 & 23 & - & - & Franscisco ve ark., 2010 \\
\hline 33,8 & 25,6 & 24 & 12,2 & 5 & Shatalov ve Pereira, 2013 \\
\hline 29,7 & 19,2 & 22,1 & - & - & Ruan ve ark., 2013 \\
\hline 39,1 & 24,4 & 19,2 & - & 4,2 & Komolwanich ve ark., 2014 \\
\hline 43,2 & 20,50 & 17,20 & - & 1,90 & Fiore ve ark., 2014 \\
\hline
\end{tabular}

Çeşitli araştırmacılar tarafından kargı kamışının temel kimyasal bileşen oranları için farklı sonuçlar bulunmuştur. Tablo 1' de görüldüğü üzere genel itibariyle kargı kamışı yapısında \%28,1 - 43,2 selüloz, $\% 19,2-29,8$ hemiselüloz, \%13,4 - 24 lignin, \%9,1 - 23,2 ekstraktif madde ve \%2,9-6,1 kül intiva eder. Diğer biyokütle kaynaklarında olduğu gibi kargı kamışının temel kimyasal bileşenleri biyokütle enerji üretimini doğrudan etkilemektedir.

Kargı kamışının temel kimyasal yapısının FTIR spektroskopisi ile desteklenmesi büyük önem taşımaktadır. Yapılan çalışmalarda örneklerin FTIR spektrumu; azaltılmış toplam yansıma (ATR) modunda veya $\mathrm{KBr}$ ile karıştırılarak analiz edilme yöntemi ile gerçekleştirilmiştir.

Şekil 4'te kargı kamışının 4000-500 $\mathrm{cm}^{-1}$ frekans aralığında alınan FTIR spektrumu görülmektedir (Galletti ve ark., 2015). Yaklaşık $3400 \mathrm{~cm}^{-1}$ 'de görülen pik, yapıda bulunan $-\mathrm{OH}$ grubuna ait gerilme pikidir. 2930-2850 $\mathrm{cm}^{-1}$ aralığındaki pikler, kargı kamışının selüloz ve hemiselüloz bileşenlerinin yapısında yer alan $-\mathrm{CH}$ ve $-\mathrm{CH} 2$ gruplarının $\mathrm{C}-\mathrm{H}$ gerilme titreşimine ait karakteristik bant iken, $1730 \mathrm{~cm}^{-1}$ 'de yer alan pik, hemiselülozdaki asetil gruplarında yer alan $-\mathrm{C}=\mathrm{O}$ gerilme titreşimi ile ilişkilendirilebilir (Şekil 4). $1506 \mathrm{~cm}^{-1}$ ve $1422 \mathrm{~cm}^{-1}$ de görülen küçük pikler ise, sırasıyla ligninin benzen halkasındaki $\mathrm{C}=\mathrm{C}$ gerilmesine ve selüloz yapısındaki $-\mathrm{CH} 2$ gruplarının bükülme titreşimine aittir. Lignin yapısındaki asetil grubunda bulunan $-\mathrm{C}-\mathrm{O}$ bağına ait gerilme titreşiminden kaynaklanan pik ise $\sim 1250 \mathrm{~cm}^{-1}$ 'de görülmektedir. Ayrıca selüloz yapısındaki piranoz halkasında yer alan C-O-C- bağına ait ve selülozdaki hidroksil ve eter gruplarındaki $-\mathrm{C}-\mathrm{O}$ bağına ait gerilme bandı sırasıyla $\sim 1080$ $\mathrm{cm}^{-1}$ ve $\sim 1035 \mathrm{~cm}^{-1}$ de görülmektedir (Fiora ve ark., 2014). Şekil 5 'te selüloz, hemiselüloz ve lignin için FTIR spektrumları gösterilmektedir.

Kargı kamışının orijinine ve yetişme yeri özelliklerine bağlı olarak yapısındaki kimyasal bileşenlerin ve oranlarının değişim göstermesi beklenen bir sonuçtur. 


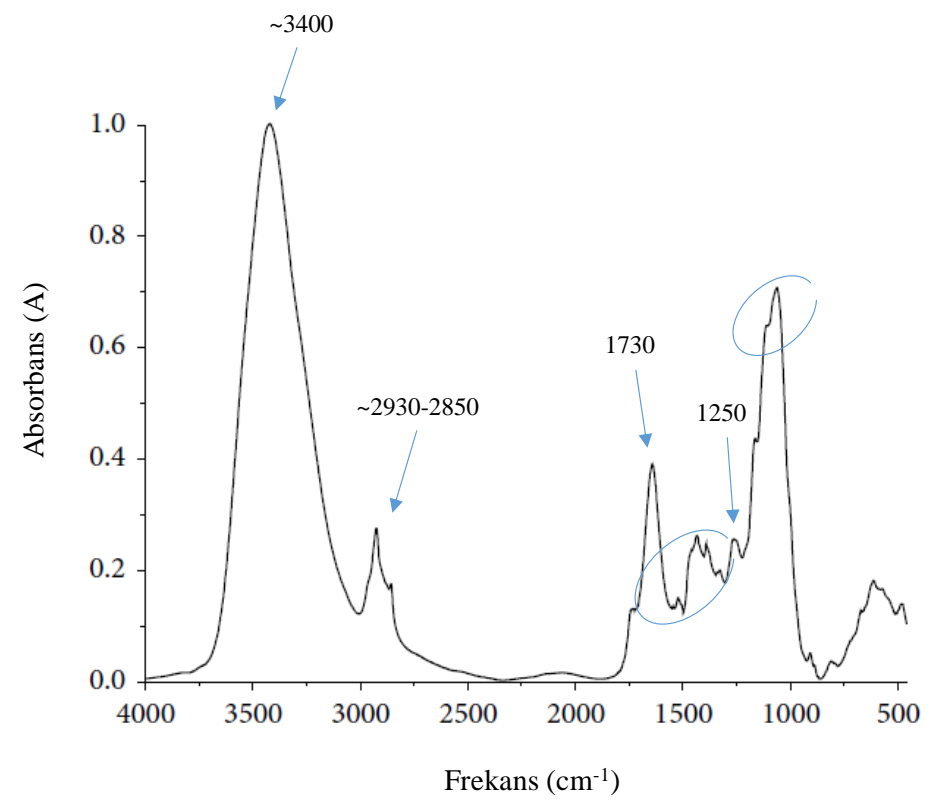

Şekil 4. Kargı kamışının FTIR spektrumu. (Galletti ve ark., 2015)
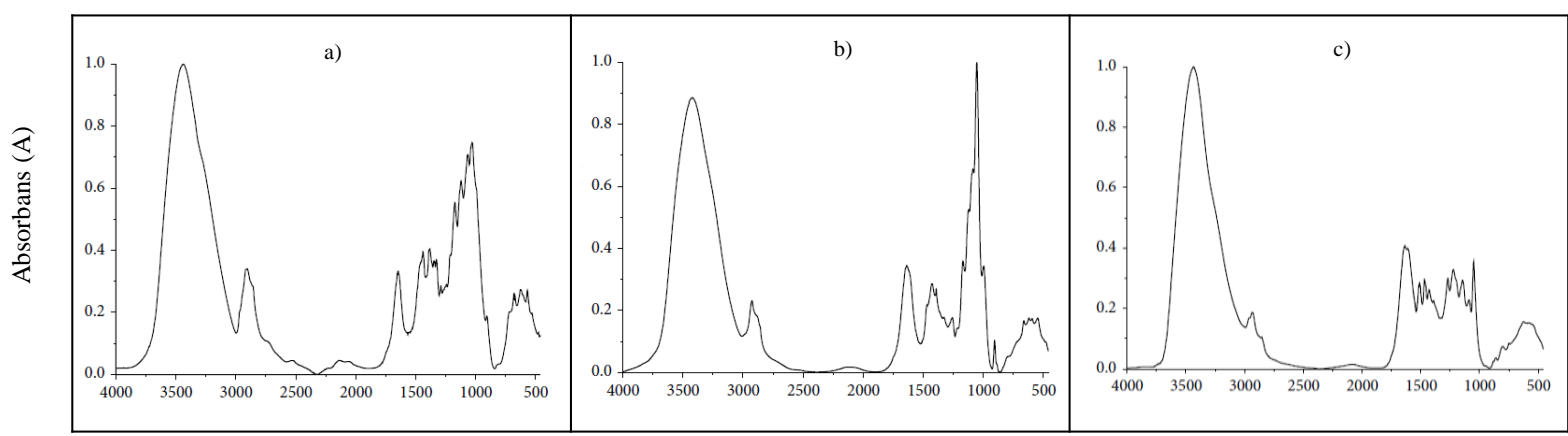

Frekans $\left(\mathrm{cm}^{-1}\right)$

Şekil 5. Selüloz (a), hemiselüloz (b) ve lignin (c) için FTIR spektrumları (Galletti ve ark., 2015)

Kargı kamışının termal özelliklerinin bilinmesi, çeşitli biyokütle dönüştürme teknikleri ve uygulama alanı açısından oldukça önemlidir. Biyokütlenin fiziksel ve kimyasal bileşenlerinin özelliklerine bağlı olarak termal karakterinde farklııklar ortaya çıkabilir. Literatürde kargı kamışının termal davranışı; en sık kullanılan termal analiz tekniklerinden biri olan termogravimetrik analiz (TGA) ile incelenmiştir. Malzemede sıcaklık artışı ile birlikte meydana gelen kütle kaybı, sıcaklık ve zamanın bir fonksiyonu olarak ölçülmektedir. Analizin gerçekleştirildiği atmosfer, termal bozunma sürecini etkileyen önemli bir parametredir.
Çoğu bitki materyali ilk yaklaşımda selüloz, hemiselüloz, lignin ve birkaç küçük bileşenin bir karışımı olarak kabul edilebilir. Genellikle düşük ısıtma hızlarında yapılan bitki materyallerinin pirolizi; nem kaybı, hemiselüloz ve selülozun bozunma aşamaları üzerinden ilerler (Connor ve ark., 1988).

Literatürde kargı kamışının oksidatif pirolizi için TGA analizi; $25-500{ }^{\circ} \mathrm{C}$ arasında $5{ }^{\circ} \mathrm{C} / \mathrm{dk}$ Isıtma hızı ile hava atmosferinde gerçekleştirilmiştir (Jeguirim ve ark., 2010). Bu koşullarda elde edilen termal bozunma eğrisi Şekil 6'da yer almaktadır. 
Gizli Kalmış Bir Enerji Kaynağı: Kargı Kamışı (Arundo donax L.)

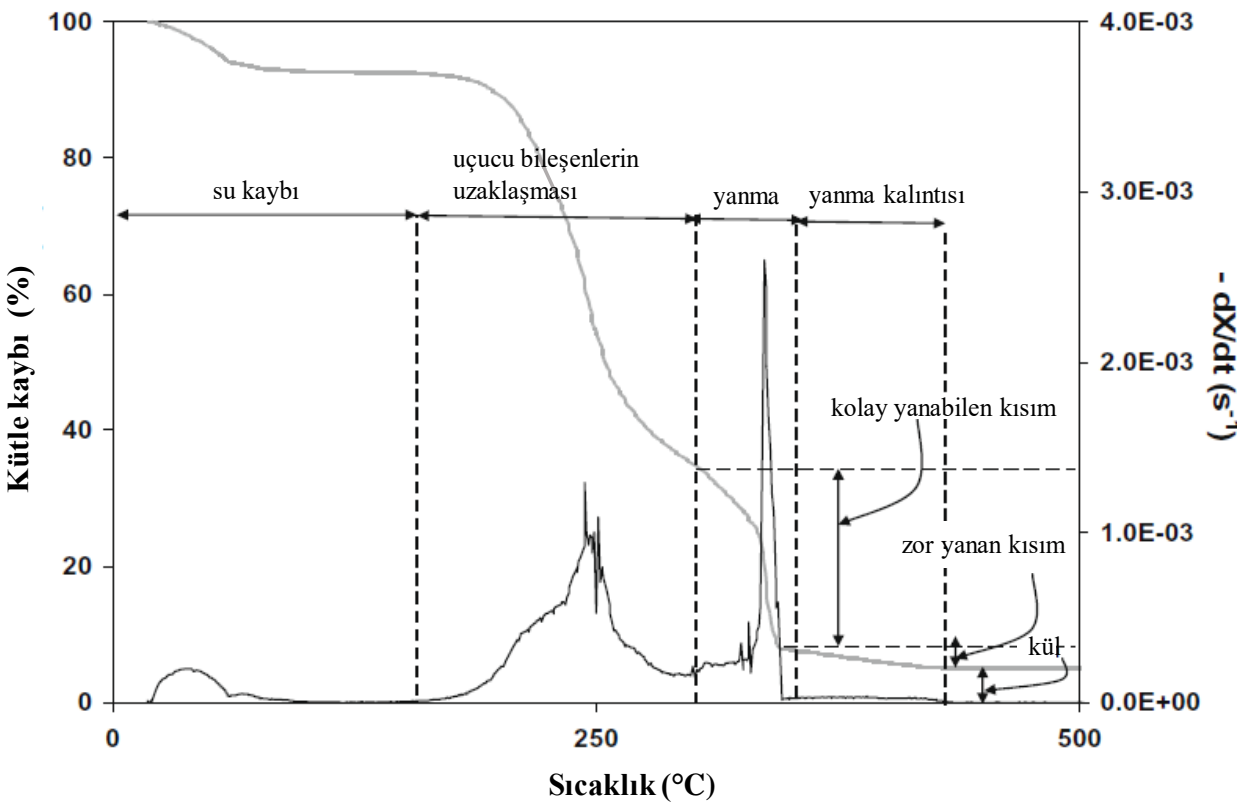

Şekil 6. Kargı kamışının hava atmosferinde elde edilen termal bozunma eğrisi (Jeguirim ve ark., 2010).

Elde edilen termogram, lignoselülozik malzemelerin oksidatif piroliz eğrilerine benzerdir (Jauhiainen ve ark., 2004; Ghaly and Ergudenler, 1991). Bozunma üç basamakta gerçekleşmektedir. 30 ile $\sim 130{ }^{\circ} \mathrm{C}$ arasında gerçekleşen ilk basamak, yapıda bulunan suyun uzaklaşmasına karşılık gelmektedir ( \%8 lik kütle kaybı). 162$300{ }^{\circ} \mathrm{C}$ arasındaki ikinci bozunuma basamağı hemiselüloz ve selülozun bozunması sırasında oluşan uçucu bileşikler ( \%58) ile ilişkilendirilir. Üçüncü basamaktaki kütle kaybı ise, karbonize olan kalıntının oksidatif bozunmasına bağlanabilir. Son basamak, uçucu maddelerin uzaklaşmasından sonra kolayca yanabilen kalıntıya ait kütle kaybı ve daha yavaş oksidasyona uğrayan kalıntıya ait kütle kaybı şeklinde iki aşamada gerçekleşebilir.
Analiz sonunda kalan kütle yanma sonucunda oluşan küle aittir.

Yapılan bir diğer çalışmada (Jeguirim ve Trouvé, 2009); kargı kamışının ısıl davranışı, $25^{\circ} \mathrm{C}$ ile $750{ }^{\circ} \mathrm{C}$ arasında, farklı ısıtma hızlarında, inert atmosfer altında termogravimetrik analiz ile incelenmiştir (Şekil 7). Bozunma iki adımda gerçekleşmektedir. $25^{\circ} \mathrm{C}$ ile $\sim 110^{\circ} \mathrm{C}$ arasında meydana gelen kütle kaybı yapıda bulunan suya aittir. $200^{\circ} \mathrm{C}$ ile $\sim 350^{\circ} \mathrm{C}$ arasında gerçekleşen, kütle kaybının en fazla olduğu ikinci basamak ise hemiselüloz ve selülozun bozunmasına karşılık gelmektedir. Bu aşamanın sonunda görülen düşük kütle kayıp oranı ise yapısından dolayı ligninin yavaş bozunmasına karşıık gelir. 


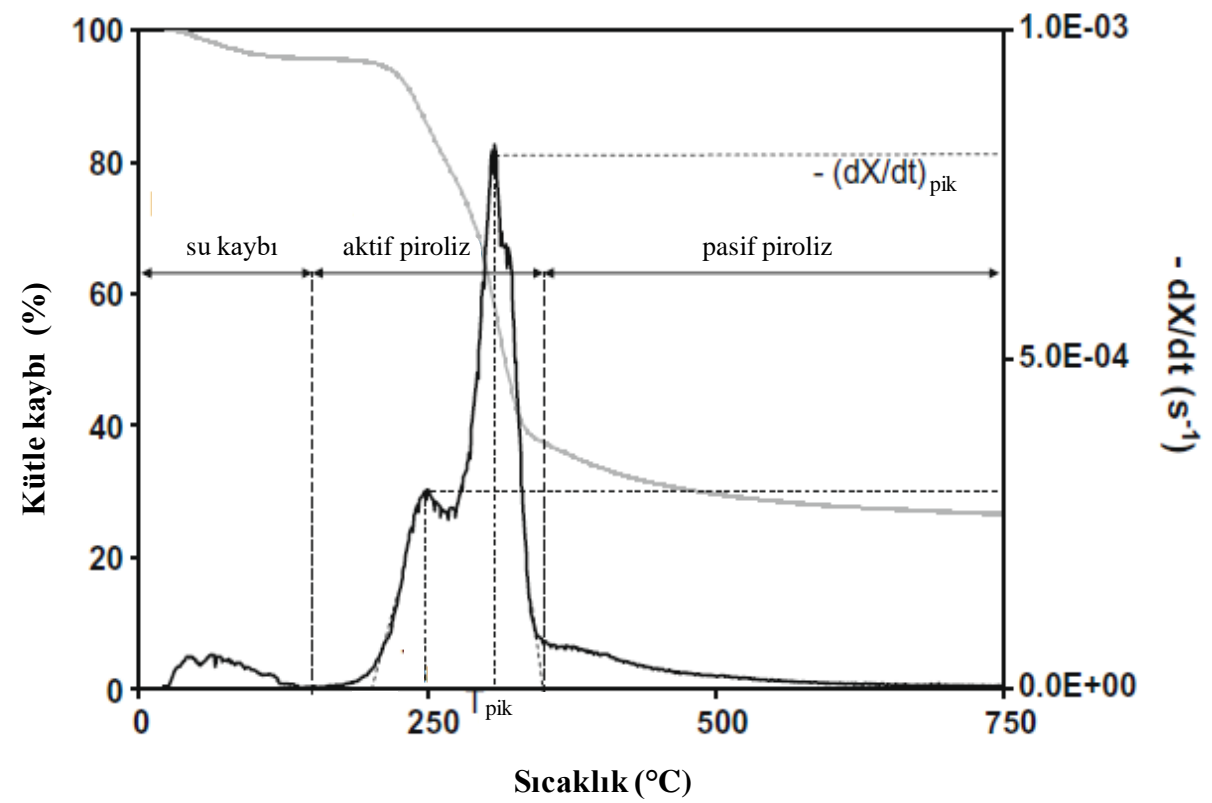

Şekil 7. Kargı kamışının inert atmosferde elde edilen termal bozunma eğrisi (Jeguirim ve Trouvé, 2009).

\section{KARGI KAMIŞININ BIYOKÜTLE DEĞERI}

Farklı yetişme ortamlarında kolayca yetişebilmesi ve her yıl hasat edilebilmesi kargı kamışını avantajlı bir biyokütle kaynağı kılmaktadır. Dünyanın çeşitli yerlerinde kargı kamışının biyokütle miktarı üzerine çalışmalar yürütülmüştür. Genel itibariyle uygun yetişme koşulları altında yıllık 100 ton/hektar kadar biyokütle sağlayabilir (Shatalov ve Pereira, 2000). Bunun yanı sıra Avustralya'da tuzlu toprakta yıllık 17,7-35,9 ton/hektar (Williams ve ark., 2008) ve İtalya'da marjinal (tarımsal ve endüstriyel değeri olmayan ya da çok az olan) arazilerde dahi üçüncü yılda 20 ton/hektar biyokütle verebilmektedir (Nassi o Di Nasso ve ark., 2013). Güneş ve Saygin (1996) Türkiye' de doğada kendiliğinden yetişen kargı kamışının hektarda yıllık 53 ton/hektar biyokütle verdiğini rapor etmişlerdir. Sulama ve gübreleme gibi müdahalelerin kargı kamışının biyokütle miktarını arttırdığı rapor edilmiştir (Angelini ve ark., 2005; Christou ve ark., 2005). Tablo 2'de kargı kamışının bazı ülkelerdeki doğal ve plantasyon alanlarındaki biyokütle miktarları verilmektedir.

Tablo 2. Ülkelere göre kargı kamışının biyokütle miktarı

\begin{tabular}{|l|l|l|l|l|}
\hline Yer & $\begin{array}{l}\text { Arazi du- } \\
\text { rumu }\end{array}$ & Hasat Yılı & Biyokütle miktarı & Yazar \\
\hline Türkiye & Doğal & - & $53 \mathrm{t} \mathrm{h}^{-1}$ & Güneş ve Saygin, 1996 \\
\hline ABD & Doğal & - & $171 \mathrm{t} \mathrm{h}^{-1}$ & Spencer ve ark. 2006 \\
\hline ABD & Doğal & - & $155 \mathrm{t} \mathrm{h}^{-1}$ & Giessow ve ark., 2011 \\
\hline Hindistan & Doğal & - & $36-167 \mathrm{t} \mathrm{h}^{-1}$ & Corno ve ark., 2014 \\
\hline İspanya & Plantasyon & $1-3$ & $1,3-45,9 \mathrm{t} \mathrm{h}^{-1}$ & Hidalgo ve Fernandez, 2000 \\
\hline Güney Fransa & - & - & $20-25 \mathrm{t} \mathrm{h}^{-1}$ & \multirow{2}{*}{ Bacher ve ark., 2001 } \\
\hline Güney Almanya & - & - & $7-26 \mathrm{t} \mathrm{h}^{-1}$ & Lewandowski ve ark., 2003 \\
\hline Yunanistan & Plantasyon & $1-4$ & $15-39 \mathrm{t} \mathrm{h}^{-1}$ & Christou ve ark., 2005 \\
\hline Yunanistan & Plantasyon & $1-3$ & $1,4-18,6 \mathrm{t} \mathrm{h}^{-1}$ & Mantineo ve ark., 2009 \\
\hline $\begin{array}{l}\text { Sicilya adası } \\
\text { (İtalya) }\end{array}$ & Plantasyon & $1-3$ & $6,1-38,8 \mathrm{t} \mathrm{h}^{-1}$ & \\
\hline Orta İtalya & Plantasyon & $2-12$ (ort) & $37,1 \mathrm{t} \mathrm{h}^{-1}$ & Angelini ve ark., 2009 \\
\hline Güney İtalya & Plantasyon & $1-2$ & $10,6-22,1 \mathrm{t} \mathrm{h}^{-1}$ & Cosentino ve ark., 2006 \\
\hline
\end{tabular}


Süreklilik arz etmesi bakımından kargı kamışı lif levha, yonga levha, kağıt hamuru, biyoyağ, biyoyakıt ve biyokütle enerjisi üretimi için ilgi çekici bir kaynak durumundadır (Arslan ve Şahin, 2014; Corno ve ark., 2014).

\section{KARGI KAMIŞININ BIYOKÜTLE ENERJISINDE KULLANIMI}

Birçok ekolojik koşulda yetişebilmesi, hızlı büyümesi, her yıl hasat edilebilmesi, yüksek biyokütle vermesi, üretim maliyetinin düşük olması gibi avantajlara sahip önemli bir gıda dışı tarım ürünü olan kargı kamışı, biyogaz, biyoetanol ve biyokütle yakma gibi biyoenerji / biyoyakıt üretim sanayi için ümit verici bir hammaddedir (Arslan ve Şahin, 2014; Corno ve ark., 2014; Brusca ve ark., 2018).

Kargı kamışının anaerobik biyogazifikasyon potansiyeli (ABP), mısır, çavdar ve tritikale (buğday ve çavdarın melezi) gibi yaygın enerji bitkilerinden daha düşük olmakla birlikte biyogaz üretimi için elverişli bir kaynaktır. Kargı kamışının ABP değeri $524 \mathrm{Nm}^{3} \mathrm{Mg}^{-1}$ iken, mısır, tritikale ve çavdar da bu değerler sırasıyla 694, 677 ve $556 \mathrm{Nm}^{3}$ $\mathrm{Mg}^{-1}$ olarak rapor edilmiştir (Corno ve ark., 2014; Schievano ve ark., 2014). Ayrıca kargı kamışından metan eldesinin ilk hasat yılı için hektarda $9580 \mathrm{Nm}^{3} \mathrm{CH}_{4}$, ikinci hasat yılı için ise $11,585-12,981 \mathrm{Nm}^{3} \mathrm{CH}_{4}$ olduğu kaydedilmiştir. (Ragaglini ve ark., 2014).

Kargı kamışından hektarda 11.000 It etanol elde edilebilmekte olup bu miktar diğer enerji bitkilerinden elde edilen etanol miktarlarına kıyasla oldukça yüksektir (Williams ve ark., 2008; Jaradat, 2010; Corno ve ark., 2014). Bununla birlikte kargı kamışından endüstriyel olarak biyoetanol üretiminin optimizasyonu, teknik ve ekonomik açıdan incelenmesi üzerine çalışmalara da ağırlık verilmiştir (Accardi ve ark., 2015; Brusca ve ark., 2018).

Biyo-metan üretim miktarının diğer enerji bitkilerinden düşük olması ve biyo-etanol üretimi öncesi ön işlemlere gereksinim duyması, kargı kamışının biyolojik fermantasyon ürünlerinde kullanımındaki dezavantajlardır. Kargı kamışından doğrudan yakma sistemi, biyo-metan ve biyo-etanol üretimine göre daha avantajlı görülmektedir.
Hektardaki biyokütle miktarı ile ısı değerinin uygun olması, kargı kamışını doğrudan yakma teknolojisi için yonga ya da pellet olarak kullanımını oldukça uygun kılmaktadır (Dahl ve Obernberger, 2004; Tenorio ve ark., 2015).

Dahl ve Obernberger (2004) kargı kamışının ısıl değerinin $(19.800 \mathrm{kj} / \mathrm{kg})$ odun pelleti ve diğer enerji bitkilerine yakın olduğunu rapor etmiştir. Tenorio ve ark (2015) Kostarika' da on iki farklı biyokütle kaynağından elde ettikleri pelletlerin ısıl değerlerini tespit etmişler ve kargı kamışı pelletinin $15.930 \mathrm{kj} / \mathrm{kg}$ ısıl değere sahip olduğunu ifade etmişlerdir. Jeguirim ve ark. (2010) kargı kamışının Isıl değerinin $17.200 \mathrm{kj} / \mathrm{kg}$ olduğunu bildirmişlerdir. Rabemanolontsoa ve Saka (2010) 29 farklı tür biyokütlenin kimyasal karakterizasyonunu yapmışlar ve kargı kamışının ısıl değerinin $20.060 \mathrm{kj} / \mathrm{kg}$ olduğunu yayınlamışlardır. Bonanno ve ark. (2013) kargı kamışının alt ısıl ve üst ısıl değerlerini sırasıyla 17.200 ve $18.400 \mathrm{kj} / \mathrm{kg}$ olarak belirlemişlerdir. Salazar-Zeledon ve ark. (2015) plantasyon ortamında 6 ayda hasat edilmiş kargı kamışının ısıl değerinin $19.505 \mathrm{kj} / \mathrm{kg}$ olduğunu ortaya koymuşlardır.

Biyokütle yakıtları yaşam döngüleri içinde tutukları karbon miktarı kadar salınım yapıyor olmaları nedeni ile biyokütle enerjisi yakma amaçlı diğer tüm enerji üretim biçimlerinden daha temiz kabul edilir. Bass ve ark. (2014) çalışma sahalarındaki kargı kamışının biyokütle miktarının yaklaşık \%22'sini toprak altı aksamın oluşturduğunu, buradan hareketle toprakta depolanan karbon miktarının 4,73 milyon ton/yıl olduğunu hesaplamışlardır. Yine bu çalışmada kargı kamışının yetiştirilmesi, hasadı, kurutulması ve yakma işlemleri (450 MW kapasiteli bir yakma tesisi için) ile 4,41 milyon ton/ yıl $\mathrm{CO}_{2}$ salınımı olduğunu hesaplamış, toprakta depolanan net karbon miktarını ise 0,32 milyon ton/ yıl olarak bildirmişlerdir.

Doğrudan yakma sistemlerinde yakıtın elementel analizi, içerdiği inorganik maddeler baca gazı ile salınacak kirleticiler, oluşacak kül ve cüruf miktarı önem taşımaktadır. Tablo 3' de kargı kamışının temel elementleri, inorganik bileşenleri, emisyon değerleri ve ısıl değerinden oluşan yakıt özellikleri verilmektedir. 
Tablo 3. Kargı kamışının yakıt özellikleri

\begin{tabular}{|c|c|c|}
\hline \multirow{5}{*}{$\begin{array}{l}\text { Temel Elementler (\%) } \\
\text { Jeguirim ve ark. (2010) }\end{array}$} & C & 42,7 \\
\hline & $\mathrm{H}$ & 7,5 \\
\hline & 0 & 48,7 \\
\hline & $\mathrm{N}$ & 0,8 \\
\hline & $S$ & 0,2 \\
\hline \multirow{8}{*}{$\begin{array}{l}\text { İnorganik Bileşenler }(\mathrm{mg} / \mathrm{kg}) \\
\text { Dahl ve Obernberger }(2004)\end{array}$} & $\mathrm{Si}$ & 13.920 \\
\hline & $\mathrm{Ca}$ & 3.253 \\
\hline & $\mathrm{K}$ & 6.497 \\
\hline & $\mathrm{Na}$ & 331 \\
\hline & $\mathrm{Mg}$ & 1.627 \\
\hline & $\mathrm{Al}$ & 919 \\
\hline & $S$ & 2.160 \\
\hline & $\mathrm{Cl}$ & 2,245 \\
\hline \multirow{4}{*}{$\begin{array}{c}\text { Salınan Gazlar* }\left(\mathrm{mg} / \mathrm{Nm}^{3}\right) \\
\text { Dahl ve Obernberger }(2004)\end{array}$} & $\mathrm{NO}_{\mathrm{x}}$ & 363 \\
\hline & $\mathrm{HCl}$ & 67 \\
\hline & $\mathrm{SO}_{2}$ & 278 \\
\hline & $\mathrm{CO}$ & 443 \\
\hline $\begin{array}{c}\text { Isıl değer (kj/kg) } \\
\text { Jeguirim ve ark. (2010); Rabemanolont }\end{array}$ & \multicolumn{2}{|c|}{$17.200-20.600$} \\
\hline
\end{tabular}

*150 kWth bir yakma ünitesinden kaynaklanan emisyon miktarlarıdır.

\section{SONUÇLAR}

Kargı kamışı birçok yönüyle avantajlı bir biyokütle kaynağıdır. Avantajları aşağıdaki gibi sıralanabilir

- Çok yıllık bir bitki olması ve üremesi için tohuma ihtiyaç duymaması

- Farklı ekolojik koşullara uyum sağlayabilmesi ve hızIıca yayılabilmesi

- Biyokütle miktarının fazla olması

- Isı enerji değerinin yüksek olması

- Depoladığı karbon miktarının salınım yaptığı karbon miktarından daha fazla olması

Biyokütle enerjisi üretiminde önemli bir hammadde kaynağı olan kargı kamışının endüstriyel olarak kullanımına yönelik Güney Avrupa ülkeleri, Kosta Rika vb. dünyanın çeşitli bölgelerinde ciddi çalışmalar yapılmaktadır. Ülkemizde ise başlıca kullanım alanları ney yapımı ve bitkisel örücülüktür. Oysaki yüksek biyokütle miktarı nedeniyle başta biyokütle enerjisi olmak üzere, lif ve yonga levha üretimi, kağıt hamuru ve kağıt üretimi için de cazip bir hammadde kaynağıdır. Biyokütle enerjisi üretimi için en uygun olduğu alan ise yonga ya da pellet olarak doğrudan yakma sistemidir. Kargı kamışının direk yakma ile ISı enerjisi üretiminde kullanılmasını sağlamak üzere farklı dönemlerde hasatı, endüstriyel amaçlı olarak uygun ekolojik koşullarda yetiştirilmesi, farklı yakma tekniklerinin belirlenmesi gibi konularda yapılacak çalışmalara intiyaç olduğu görülmektedir. Kargı kamışından ısı ener- jisi üretiminin endüstriyelleştirilmesi için teknik ve ekonomik çalışmalara vakit kaybetmeden başlanılması çok önemli bir husustur.

\section{KAYNAKLAR}

Accardi D.S., Russo P., Lauri R., Pietrangeli B., Di Palma L. (2015). From soil remediation to biofuel: process simulation of bioethanol production from arundo donax. Chemical Engineering Transactions, 43: 2167-2172.

Altheimer, E., Wolcott, M. (1999). Arundo donax pulp, paper products, and particleboard. Alex-Alt Biomass, Inc (US) Patent WO 99/066119, Dec, 23, 1999

Angelini, L.G, Ceccarini, L, Bonari, E. (2005). Biomass Yield and Energy Balance of Giant Reed (Arundo Donax L.) Cropped in Central Italy as Related to Different Management Practices. European Journal of Agronomy, 22: 37538.

Angelini, L.G, Ceccarini, L, Di Nasso, N,N, Bonari, E. (2009). Comparison of Arundo donax L. and Miscanthus x Giganteus in a Long-Term Field Experiment in Central Italy: Analysis of Productive Characteristics and Energy Balance. Biomass and Bioenergy, 33:635-43.

Arslan, M.B., Şahin, H.T. (2014). Alternatif Hammadde Kaynağı Olarak Kargı Kamışı (Arundo donax L.) Üzerine Bir İnceleme. Süleyman Demirel Üniversitesi, Fen Bilimleri Enstitüsü Dergisi, 18(3): 90-96.

Arslan, M.B. (2011). İklim Değişikliği ve Odun Enerjisi Kullanımı. Orman Mühendisliği, 1-2-3: 37-42.

Arslan, M., Üremiş, İ., Şener, O., Bozkurt, S., Dağhan, H., 2012. Hatay Illi Samandağ İlçesi Ney Kamışıklarının Durumu ve Sürdürülebilirliği. Mustafa Kemal Üniversitesi Ziraat Fakültesi Dergisi, 17 (2): 87-96. 
Bacher, W., Sauerbeck, G., Wagner, G.M., Bassam, N.E. (2001). Giant Reed (Arundo donax) Network, Improvement, Productivity and Biomass Quality. Final Report FAIR CT96-2028, Braunschweig, $72 \mathrm{p}$.

Bass, R., Garcia-Perez,M., Horneck,D., Lewis, M., Pan, B., Peters, T., Stevens,B., Wysocki, D. (2014). Carbon Implications of Converting a Coal-Fired Power Plant to Combustion of Torrefied Arundo donax. Appl. Bioenergy, 1: 30-43

Bezirci, Z. (2007). Göller Bölgesi'nde Bitkisel Dokumacılık Ve Üretilen Hasır Dokumaların Bazı Özellikleri Üzerinde Bir Araştırma, Doktora Tezi, Ankara Üniversitesi, Ankara.

Bonanno, G., Cirelli, G.L., Toscano, A., Lo Giudice, R., Pavone, P. (2013). Heavy metal content in ash of energy crops growing in sewage-contaminated natural wetlands: Potential applications in agriculture and forestry? Science of the Total Environment, 452-453: 349-354.

Brusca, S., Cosentinob, S.L., Famosob, F., Lanzafameb, R., Maurob, S., Messinab, M., Scandura, P.F. (2018). Second generation bioethanol production from Arundo donax biomass: an optimization method. Energy Procedia, 148: 728735.

Caparròs, S., Ariza, J., Lòpez, F., Dìaz, M.J. (2007). Optimizing cellulosic paper obtained from Arundo donax L. under hydrothermal treatment. Journal of Industrial and Engineering Chemistry, 13:465-73.

Cervelli, E., Pindozzi, S., Capolupo, A., Okello, C., Rigillo, M., Boccia, L. (2016). Ecosystem services and bioremediation of polluted areas. Ecological Engineering, 87: 139-149.

Christou M., Mardikis, M., Alexopoulou, E. (2005). Biomass production from perennial crops in Greece. In: Proceedings of the 14th European conference and technology exhibition on biomass for energy, Industry and Climate Protection, 17-21 October, Paris.

Connor, M.A., Salazar, C.M. (1988). Factors Influencing the Decomposition Processes in Wood Particles during Low Temperature Pyrolysis. In Research in Thermochemical Biomass Conversion. Bridgewater, A.V., Knester, J.L. (eds.), Elsevier, London, pp. 164-178.

Corno, L., Pilu, R., Adani, F. (2014). Arundo donax L. A nonfood crop for bioenergy and bio-compound production, $B i-$ otechnology Advances, 32(8): 1535-1549.

Cosentino, S.L., Copani, V., D'Agosta, G.M., Sanzone, E., Mantineo, M. (2006). First results on evaluation of Arundo donax L. clones collected in Southern Italy. Industrial Crops and Products, 23:212-222.

Cristaldi, A., Conti, G.O., Jho, E.H., Zuccarello, P., Grasso, A., Copat, C., Ferrante, M. (2017). Phytoremediation of contaminated soils by heavy metals and PAHs. A brief review. Environmental Technology \& Innovation, 8: 309-326.

Ferrandez-García, M.T., Ferrandez-Garcia, A., Garcia-Ortuño, T., Ferrandez-Garcia, C.E., Ferrandez-Villena, M. (2020). Assessment of the Physical, Mechanical and Acoustic Properties of Arundo donax L. Biomass in Low Pressure and Temperature Particleboards. Polymers, 12: 1361.

Fiore, V., Scalici, T., Valenza, A. (2014). Characterization of a new natural fiber from Arundo donax L. as potential reinforcement of polymer composites, Carbohydrate Polymers, 106: 77-83.

Franscisco L, Carlos GJ, Antonio P, Javier FM, Minerva AMZ, Gil G. (2010). Chemical and energetic characterization of species with a high-biomass production: Fractionation of their components. Environmental Progress and Sustainable Energy, 29:499-509.

Galletti, A.M.R., D'Alessio, A., Licursi, D., Antonetti, C., Valentini, G., Galia, A., Nicoletta Nassi o Di Nasso, N. (2015). Midinfrared FT-IR as a Tool for Monitoring Herbaceous Biomass Composition and Its Conversion to Furfural. Journal of Spectroscopy, 15: 1-12.

GBIF Secretariat. 2021. GBIF backbone taxonomy: Arundo donax L. Global Biodiversity Information Facility, Copenhagen, Erişim: https://www.gbif.org/species/2703041, (Mart 2021).

Ghalehno, M.D., Madhoushi, M., Tabarsa, T., Nazerian, M. (2011). The Manufacture of Particleboards Using Mixture of Reed (Surface Layer) and Commercial Species (Middle Layer). European Journal of Wood and Wood Products, 69: 341-344.

Ghaly, A.E., Ergudenler, A. (1991). Thermal degradation of cereal straws in air and nitrogen. Journal of Applied Biochemistry and Biotechnology, 27: 111-126.

Giessow, J., Casanova, J., Lecler, R., MacArthur, R., Fleming, G. (2011). Arundo donax - Distribution and impact report. California Invasive Plant Council.

Gordon, D.R., Tancig, K.J., Onderdonk, D.A., Gantz, C.A. (2011). Assessing the Invasive Potential of Species Proposed for Florida and the United States Using the Australian Weed Risk Assessment. Biomass Bioenergy, 35:74-79.

Guarrera, P.M. (2008). Handicrafts, Handlooms and Dye Plants in Italian Folks Tradition. Indian Journal of Traditional Knowledge, 7: 67-69.

Gücel S. (2010). Arundo donax L. (Giant reed) Use by Turkish Cypriots. Ethnobotany Research and Applications, 8: 245248.

Güneş, K., Saygin, Ö. (1996). Productivity of the Energy Crops: Giant Reed and Sweet Sorghum in Turkey. Fresenius Environmental Bulletin, 5: 756-761.

Hidalgo, M., Fernandez, J. (2000). Biomass Production of Ten Populations of Giant Reed (Arundo donax L.) Under the Environmental Conditions of Madrid (Spain). Biomass for Energy and Industry: Proceeding of the First World Conference, Sevilla, Spain. London: James \& James (Science Publishers) Ltd., p. 1881-1884.

Jaradat, A.A. (2010). Genetic resources of energy crops: Biological system to combat climate change. Australian Journal of Crop Science, 4: 309-323.

Jauhiainen, J., Conesa, J.A., Font, R., Martín-Gullón, I. (2004). Kinetics of the pyrolysis and combustion of olive oil solid waste. Journal of Analytical and Applied Pyrolysis, 72: 915.

Jeguirim, M., Dorge, S., Trouvé, G. (2010). Thermogravimetric analysis and characteristics of two energy crops in air atmosphere: Arundo donax and Miscanthus giganteus. Bioresource Technology, 101:788-793.

Jeguirim, M., Trouvé, G. (2009). Pyrolysis characteristics and kinetics of Arundo donax using thermogravimetric analysis, Bioresource Technology, 100: 4026-4031.

Koca, F. (2002). Ney'in Tarihi Gelişimi ve Dini Musikimizdeki Yeri. Dini Araştırmalar, 4: 181-96.

Komolwanich, T., Tatijarern, P., Prasertwasu, T., Khumsupan, D., Chaisuwan, T., Luengnaruemitchai, A., Wongkasemjit, S. (2014). Comparative potential of Kans grass (Saccha- 
rum spontaneum) and Giant reed (Arundo donax) as lignocellulosic feedstocks for the release of monomeric sugars by microwave/chemical pretreatment. Cellulose, 21:13271340.

Lewandowski, I., Scurlock J.M.O, Lindvall E, Christou M. (2003). The Development and Current Status of Perennial Rhizomatous Grasses As Energy Crops in the US and Europe. Biomass and Bioenergy, 25: 335-361.

Mantineo, M., D’Agosta G.M., Copani, V., Patane, C., Cosentino, S.L. (2009). Biomass Yield and Energy Balance of Three Perennial Crops for Energy Use in the Semi-Arid Mediterranean Environment. Field Crops Research, 114:20413.

Nassi o Di Nasso, N., Roncucci, N., Bonari, E. (2013). Seasonal dynamics of aboveground and belowground biomass and nutrient accumulation and remobilization in Giant Reed (Arundo donax L.): A threeyear study on marginal land. BioEnergy Research, 6: 725-736

Neto, C. P., Seca, A., Nunes, A.M., Coimbra, M.A., Domingues, F., Evtuguin, D., Silvestre, A., Cavaleiro, J.A.S. (1997). Variations in Chemical Composition and Structure of Macromolecular Components in Different Morphological Regions and Maturity Stages of Arundo donax. Industrial Crops and Products, 6: 51-58.

Odero, D., Robert, R., Ferrell, J., Helsel, Z. (2011). Production of Giant Reed for Biofuel. Agronomy Department, Florida Cooperative Extension Service, University of Florida, SS AGR-318. Original publication date November 2008. Revised November, $p, 4$.

Ortunõ, T.G., Rodrígues, J.A., García, M.T.F., Villena, M.F., García, C.E.F. (2011). Evaluation of the Physical An Mechanical Properties of Particleboard Made from Giant Reed (Arundo donax L.). BioResources, 6: 477-486.

Perdue, R.E. (1958). Arundo donax-Source of Musical Reeds and Industrial Cellulose. Economic Botany, 12: 368-404.

Pilu, R., Manca, A., Landoni, M. (2013). Arundo donax As an Energy Crop: Pros and Cons of the Utilization of This Perennial Plant. Maydica, 58: 54-59.

Quinn, L.D., Holt, J.S. (2008). Ecological Correlates of Invasion by Arundo donax in Three Southern California Riparian Habitats. Biological Invasions, 10: 591-601.

Ragaglini, G., Dragoni, F., Simone, M., Bonari, E. (2014). Suitability of giant reed (Arundo donax) for anaerobic digestion: Effect of harvest time and frequency on biomethane yield potential. Bioresource Technology, 152:107-115.

Rabemanolontsoa, H., Saka, S. (2013). Comparative study on chemical composition of various biomass species. Royal Society of Chemistry Advances, 3:3946-3956.

Ramos, D., Salvadó, J., and Fernando, F. (2017). High mechanical performance boards made from fibers of Arundo donax without added adhesives. Bioresource Technology, 12(3): 5383-5394.
Ruan, Z., Zanotti, M., Zhong, Y., Liao, W., Ducey, C., Liu, Y. (2013). Co-Hydrolysis of Lignocellulosic Biomass Microbial Lipid Accumulation. Biotechnology and Bioengineering, 110: 1039-1049.

Salazar-Zeledon, E., Moya-Roque, R., Valaert, J. (2015). Biomass and Bioenergy Production of Arundo donax L., Pennisetum purpureum Schum. and Pennisetum purpureum Schumack. X Pennisetum glaucum L. in Short Rotation Cropping System in Costa Rica. Journal of Biobased and Bioenergy, 9: 1-8.

Schievano, A., D'Imporzano, G., Orzi, V., Colombo, G., Maggiore. T., Adani, F. (2015). Biogas from dedicated energy crops in Northern Italy: electric energy generation costs. Global Change Biology Bioenergy, 7:899-908.

Shatalov, A.A, Pereira, H. (2000). Arundo donax L. (Giant Reed) as a Source of Fibres for Paper Industry: Perspectives for Modern Ecologically Friendly Pulping Technologies. Biomass for Energy and Industry: Proceeding of the First World Conference, Sevilla, Spain. London: James \& James (Science Publishers) Ltd., p. 1183-1186.

Shatalov, A.A., Pereira, H. (2001). Arundo donax L. ReedNew Perspectives for Pulping and Bleaching. 2. Organosolv Delignification. Tappi Journal, 84(11): 1-14.

Shatalov, A.A., Pereira, H. (2013). High-Grade Sulfur-Free Cellulose Fibers by Pre-Hydrolysis and Ethanol-Alkali Delignification of Giant Reed (Arundo donax L.) Stems. Industrial Crops and Products, 43: 623-630.

Shatalov, A.A., Quilhó, T., Pereira, H. (2001). Arundo donax L. Reed: New Perspectives for Pulping and Bleaching 1. Raw Material Characterization. Tappi Journal, 84(1): 1-12

Soyak, A. (2009). Aşağı Seyhan Ovası Sulama Sistemlerindeki Yabancı Otlanma ve Yabancı Ot Türleri İle Üzerindeki Doğal Düşmanların Saptanması, Yüksek Lisans Tezi, Çukurova Üniversitesi, Adana.

Spencer, D.F., Liow, P.S., Chan, W.K., Ksander, G.G., Getsinger, K.D. (2006). Estimating Arundo donax shoot biomass. Aquatic Botany, 84:272-276.

Tenorio, C., Moya, R., Tomazello Filho, M., Valaert, J. (2015). Quality of pellets made from agricultural and forestry crops in Costa Rican tropical climates. Bioresource Technology, 10(1): 482-498.

Ververis, C., Georghiou, K., Christodoulakis, N., Santas, P., Santas, R. (2004). Fiber Dimensions, Lignin and Cellulose Content of Various Plant Materials and Their Suitability for Paper Production. Industrial Crops and Products, 19: 245254.

Williams, C.M.J., Biswas, T.K., Schrale. G., Virtue, J.G., Heading, S. (2008). Use of saline land and wastewater for growing a potential biofuel crop (Arundo donax L.). Proceedings of Irrigation Australia Conference, May 20-22, Melbourne 